\title{
Low vision rehabilitation: current perspectives
}

This article was published in the following Dove Press journal:

Clinical Optometry

20 August 2015

Number of times this article has been viewed

\section{Enzo Maria Vingolo Vittoria De Rosa Daniela Domanico Federico Anselmucci \\ Department of Ophthalmology, University La Sapienza of Rome, Terracina, Italy}

Correspondence: Vittoria De Rosa via Luigi Boccherini 4, 04I00 Latina, Italy Tel +39393565 8199

Email vittoria.dr@libero.it
Abstract: Quality of life in low vision patients is deeply conditioned by their visual ability, and increased rates of depression, domestic injury, and need for caregiver assistance can be expected as a result of low performance. Much effort have been made recently in order to develop new tools and aids for rehabilitation of low vision, and this research has led to better knowledge of visual function and increased the likelihood of new therapies in the future. Modern low vision rehabilitation is the result of recent advances in science and technology, and will soon have an important role in people with vision impairment, numbers of whom are likely to increase, give the increasing age of the population. This review outlines scientific developments in low vision rehabilitation based on a search of the literature, covers the role of digital technology and advances in neurofunctional rehabilitation, and the possibility of restoring vision by use of retinal prostheses and cellular therapy.

Keywords: AMD, retinal dystrophy, biofeedback training, retinal prosthesis, stem cells

\section{Introduction}

Low vision is considered by definition to be "permanent vision impairment that is not correctable by spectacles, contact lenses, or medical and surgical intervention". ${ }^{1}$ There are 191-285 million patients affected by visual impairment worldwide, with 80 million needing low vision care, ${ }^{2-5}$ and this number is expected to grow to 200 million by 2020 , equating to $1 \%-2 \%$ of Europeans, because of the world's ageing population and improvements in pharmacological and surgical tools that can reduce the rate of blindness. The most frequent causes of low vision are macular degeneration, diabetic retinopathy, pathological myopia, glaucoma, retinitis pigmentosa, and retinal dystrophy. ${ }^{6}$

Loss of vision negatively impacts the patient's quality of life, with increased rates of depression, need for caregiver assistance, and risk of multiple falls; these observations have been made by many researchers, with reports that approximately one-third of older patients with low vision experience clinically significant symptoms of depression. ${ }^{7,8}$ For this reason, much effort has recently been devoted to developing new tools and aids for low vision rehabilitation, leading to better knowledge of visual functions and increasing the likelihood of new therapies in the future.

Modern low vision rehabilitation will become increasingly important in the upcoming years as the world's population continues to age. This review of the literature outlines recent scientific developments in the field of low vision rehabilitation, along with the principles, details, and outcomes of emerging technologies. 


\section{Improved digital technology helps low vision rehabilitation}

The Low Vision Rehabilitation Outcomes Study from the Wilmer Eye Institute reported that $64 \%$ of patients affected by low vision report difficulty with reading as their main impediment. ${ }^{9}$ Therefore, many low vision experts have suggested the use of electronic books as possible aids. ${ }^{10,11}$ In the last 5 years, smartphones, tablets, and electronic books have become widely available for the general population, and it has been observed that people with impaired vision can be helped considerably by these devices when the contrast or light on the screen is modified. This observation is supported by the results of a study of 27 patients with wet age-related macular degeneration by Gill et al, who showed that patients read faster on an Apple iPad with enlarged text than on paper. This is because of the higher contrast and brighter background on the screens of these devices. ${ }^{12}$

Further, a number of apps have been designed specifically for patients with low vision. The TapTapSee ${ }^{13}$ and VizWiz ${ }^{14}$ are apps used to take pictures of objects and provide an audio description of the pictures taken. The Optelec Magnifier $\mathrm{app}^{15}$ allows patients to magnify and increase the contrast of text and pictures.

The MD_evReader app was developed with the specific aim of assisting the eccentric viewing technique adopted by patients with age-related macular degeneration. This app allows dynamic text presentation by presenting one line of text at a time, reducing the need for eye movements, and contributes to suppressing the natural inclination to make saccades that limit the patient's view. This app also enables a visible marker to be placed on the screen in order to help the low vision reader to maintain their place within the text. ${ }^{16}$ It should be borne in mind that the rapid technological advances being made will lead to equally rapid development of new apps.

New techniques known as "vision multiplexing" have been developed to help people with tunnel vision and loss of central vision. These devices work by increasing the field of vision using a head-mounted display. The patient can see through the screen, which increases the portion of space perceived. ${ }^{17,18}$ Thus, people with tunnel vision are helped by adding an image of the surrounding area on the head-up display in order to be able to maintain central resolution while exploring the remaining visual field. ${ }^{19,20}$

The head-mounted display can also help people with impairment of central vision by magnifying the contrast on the screen; several head-mounted display devices with this function have been designed, including the Low Vision
Enhancement System, ${ }^{21}$ Jordy, Flipperport, and NuVision. ${ }^{22}$ However, although these head-mounted display devices are able to improve the patient's visual acuity, they are not suitable for use with a mobile, because the enlarged image makes it difficult walking while wearing a device. To overcome this problem, Luo and Peli have developed a portable prototype device with an optical see-through screen that allows the patients to look through the screen with diminished interference with sight. ${ }^{20}$

The latest development in the field of wearable headmounted display systems is Google Glass. This is a small computer mounted on a frame with a "wide angle camera" and a tight see-through display that looks like spectacles. It works as a telescope with an audio describer. Hwang and Peli have investigated the possibility of using Google Glass as a visual aid for patients with visual impairment, since it increases edge enhancement, thus opening up a new opportunity for developing useful devices at a reasonable cost. ${ }^{23}$ However, a recent study showed that, compared with regular spectacles, the head-mounted device obstructs peripheral vision, probably because of the pronounced frame, demonstrating that the effects of this device on vision are still largely unknown. ${ }^{24}$ Future options that might be accessible include haptic icons on touchscreens and smartphone apps based on audio systems with an automatized face recognition system for blind patients. The main obstacles to use of such devices nowadays are their high cost and limited knowledge of how helpful these devices could actually be for patients. However, the number of new possible technological solutions in this field will increase in the near future.

\section{Neurofunctional rehabilitation}

Several studies have demonstrated a direct relationship between improved visual acuity and better fixation stability, ${ }^{25-27}$ people with central vision loss have diminished fixation stability related to their low vision. ${ }^{27,28}$

Most patients with loss of central vision cope with their impairment by using more eccentric parts of the healthy retina to fixate. This new retinal fixation area is known as the preferred retinal locus (PRL). ${ }^{29}$ It is assumed that improving fixation stability and training patients to use a healthy part of the retina for fixation could improve visual performance. This is the goal of current low vision rehabilitation programs devised to improve retinal sensitivity and fixation using biofeedback strategies.

Biofeedback is a method for controlling a nonvoluntary parameter with the aid of acoustic stimulation. In the past, a number of biofeedback training approaches have 
been proposed for visual rehabilitation, ranging from basic systems like the biofeedback integrated system device ${ }^{30,31}$ to more complex systems like the VisualPathfinder, MP-1, and MAIA $^{32}$ microperimeter devices The latter system includes computerized perimetry, a measurement of fixation stability, and digital fundus photography, all under the control of an auditory biofeedback system. As the patient comes closer to a fixation point chosen by the ophthalmologist, the more continuous the audio biofeedback becomes; in this way, patients can be trained to use a new PRL to fix the target. This is made possible by cerebral plasticity and neurosensory adaptation to the central scotoma. In a study of 25 eyes with age-related macular degeneration, Vingolo et al showed that this instrument could improve visual acuity, fixation behavior, retinal sensitivity, and reading speed. Five training sessions, each lasting 10 minutes and given at 3-month intervals, are recommended when using the MP-1 microperimeter device to maintain improved visual performance. ${ }^{33}$ Similar results were subsequently reported for five patients with several types of macular disease (vitelliform dystrophy, post-traumatic macular scar, Stargardt disease, myopic macular degeneration, cone dystrophy), confirming the results of the previous study. ${ }^{34}$ An interesting finding was that patients were able to fixate with both the new and the old PRL after a biofeedback training session, despite the fact that they were not trained to use this location. ${ }^{35}$

Encouraging results were also obtained in a patient with oculocutaneous albinism. However, the improved fixation stability in this patient was not associated with an improvement in functional responses, such as best corrected visual acuity and mean retinal sensitivity. ${ }^{36}$

In 2013, Vingolo et al used this rehabilitation strategy for the first time to treat myopic maculopathy and central scotoma. They carried out a pilot study in which they combined acoustic biofeedback training with the MP-1 microperimeter and the Visual Pathfinder A10, based on the observation that microperimetric biofeedback stimulates more stable fixation by training the retina to maintain a target retinal location, whereas the Visual Pathfinder presents an iterative stimulation that forces ganglion cells and receptive fields to improve axonal transmission through the geniculate body and brain. The results showed significant improvement of best corrected visual acuity, retinal sensitivity, and fixation behavior. ${ }^{37}$ The effects of auditory biofeedback on visual training have also been exploited in optic neural dysfunction due to glaucoma ${ }^{38}$ and in posterior microphthalmos. ${ }^{39}$

The above-mentioned studies demonstrate that audio feedback improves the patient's conscious attention by increasing the time for which the fixation target remains on the retina. In this way, training helps the brain to use input from a new PRL to reach the foveal occipital cortex, probably by facilitating transmission of stimuli between intraretinal neurons and between the retina and the brain.

The MP-1 microperimeter device is a different biofeedback strategy based on a structured pattern stimulus. It consists of a black and white checkerboard superimposed on the fixation target. Patients are asked to look at the fixation target and the stimulus flickers when they fix with the desired PRL. The usefulness of the flickering visual stimulus has been evaluated in the treatment of hemianopic visual field loss ${ }^{40,41}$ and for visual rehabilitation in patients with retinitis pigmentosa. ${ }^{42}$ When compared with acoustic biofeedback, this technique seems to provide better results in terms of best corrected visual acuity, reading speed, and fixation behavior. ${ }^{43}$

Some hypotheses can be put forward to explain the mechanism by which this technique improves visual performance. Imaging studies indicate that the visual cortex in patients with age-related macular degeneration shows signs of cortical reorganization in areas of the cortex that topographically match the fovea. ${ }^{44,45}$ Cortical regions that previously processed only foveal visual information could be activated by peripheral stimuli, and this reorganization is associated with development of eccentric vision. It is therefore supposed that repeated stimulation induces synaptic plasticity in the partially damaged structures, and stabilizes their synchronous firing beyond the treatment period. This improved or stabilized synchronization is one of the proposed neurophysiological mechanisms of restoration of vision. ${ }^{46}$ Further, it is possible that both the MP-1 and the Visual Pathfinder influence oculomotor performance in patients with visual impairment, which might be deficient when they attempt to redirect incoming images to the area with the highest retinal sensitivity. In this way, these techniques might improve the performance of the oculomotor system by increasing the number of correct saccade movements. Although there is no validated scientific theory concerning the actual mechanism of action of biofeedback training, the results obtained in these studies are very encouraging and contribute significantly to clinical practice and research in patients with low vision.

\section{Rehabilitation of ultra-low vision}

Nowadays, improvements in technology and materials make retinal replacement to restore sight possible. Many attempts have been made to improve the remaining functioning retina in patients by electrical stimulation. The two models of 
retinal prostheses available are the Argus II retinal prosthesis system and the Alpha-IMS. The main difference between these two devices lies in the methods used to obtain continuous visual inputs, ie, the Argus II uses an external camera to capture the surroundings and processes the images in real time using computer algorithms to convert them into an electrical signal, ${ }^{47}$ and the Alpha-IMS uses the patient's cornea and lens to focus the visual images directly onto a photodiode. ${ }^{48}$ Both devices work by stimulating nerve endings using a microelectrode array that activates voltagegated ion channels in neurons. The Argus II microelectrode array is implanted epiretinally and is made of 60 circular microelectrodes $200 \mu \mathrm{m}$ in diameter, each covering an area of hundreds of photoreceptors. In contrast, the Alpha-IMS implant is placed subretinally and consists of a microphotodiode array containing 1,500 photosensitive pixel-generating elements. The subretinal implants directly stimulate bipolar cells in the way that photoreceptors do naturally, and this is the main benefit of such devices, ie, they allows the natural process of vision to occur by activation of ganglion cells. However, it is not possible to stimulate retinal bipolar cells individually because of the relatively large dimensions of the electrodes. Further, according to Chen et al, ${ }^{49}$ whether positioning of the microelectrodes is epiretinal or subretinal is irrelevant, because in both cases the stimulation spreads through the entire retina, stimulating both bipolar and ganglion cells.

Regardless of the external image capturing system used, the main criticism of this method is that capturing of the image is independent of the position of the eyes. However, there is some evidence suggesting that results using the Argus II are not affected by impairment of mobility or orientation. ${ }^{50,51}$ Further, unlike the Alpha-IMS implant, the Argus-II helps to restore physiological patients' transduction that may be damaged by the pathology. ${ }^{52}$

Humayun et al have reported the results of a clinical trial evaluating the Argus II retinal prosthesis system in 30 patients with severe outer retinal degeneration. All subjects in this study were able to perceive stimuli throughout the entire follow-up period, and $96 \%$ were able to localize high-contrast objects on a computer screen more easily while the Argus II was on than when it was off. ${ }^{47}$ da Cruz et al have reported similar results showing that patients are able to identify letters and words using the Argus II device. ${ }^{53}$ Zrenner et al have studied the outcome of subretinal implants, and shown that blind patients using these devices are able to identify bright objects on a dark table as well as describe and name common objects. ${ }^{48}$
The most common adverse events reported in the literature to be associated with surgical implantation of these devices are conjunctival dehiscence, conjunctival erosion, presumed endophthalmitis, and hypotony. However, the safety profile of these prostheses is comparable with that of similar implantable devices, such as those used for glaucoma drainage. ${ }^{47}$

The main limitation of these retinal implants is that they are designed only to take over the role of damaged photoreceptor cells. Therefore, people with other causes of blindness, such as diabetic retinopathy, severe optic atrophy, retinal detachment, glaucoma, stroke, or trauma, are not eligible for retinal implants. The main obstacle to everyday use of these implants remains the lack of information due to the ongoing clinical trials and studies. Further studies are needed to compare the final long-term outcomes using the various devices.

\section{Conclusion}

Recent research has brought about a good deal of change in the field of low vision rehabilitation and our paper tried to resume the actual trends on this topic. It is estimated that the number of people affected by low vision will continue to increase in the future, and it is hoped that this paper will generate further research in this important area.

\section{Disclosure}

None of the authors have financial or proprietary interests in any materials or methods mentioned in this work.

\section{References}

1. Raasch TW, Leat SJ, Kleinstein RN, Bullimore MA, Cutter GR. Evaluating the value of low-vision services. J Am Optom Assoc. 1997;68(5):287-295.

2. Resnikoff S, Pascolini D, Etya'ale D, et al. Global data on visual impairment in the year 2002. Bull World Health Organ. 2004;82(11):844-851.

3. Bourne RR, Stevens GA, White RA, et al. Causes of vision loss worldwide, 1990-2010: a systematic analysis. Lancet Global Health. 2013;1(6):e339-e349.

4. Pascolini D, Mariotti SP. Global estimates of visual impairment: 2010. Br J Ophthalmol. 2012;96(5):614-618.

5. Stevens GA, White RA, Flaxman SR, et al. Global prevalence of vision impairment and blindness magnitude and temporal trends, 1990-2010. Ophthalmology. 2013;120(12):2377-2384.

6. Sánchez Ferreiro AV, Miguéns Vázquez X. Letter to the editor. Visual rehabilitation in low vision. Arch Soc Esp Oftalmol. 2013;88(3):123-124.

7. Brody BL, Gamst AC, Williams RA, et al. Depression, visual acuity, comorbidity, and disability associated with age-related macular degeneration. Ophthalmology. 2011;108(10):1893-1900.

8. Horowitz A, Reinhardt JP, Boerner K, Travis LA. The influence of health, social support quality and rehabilitation on depression among disabled elders. Aging Ment Health. 2003;7(5):342-350.

9. Rubin G. Vision rehabilitation for patients with age related macular degeneration. Eye. 2001;15 Part 3:430-435.

10. Crossland MD, Macedo AF, Rubin GS. Electronic books as low vision aids. Br J Ophthalmol. 2010;94(8):1109. 
11. Crossland MD, Rui SS, Macedo AF. Smartphone, tablet computer and e-reader use by people with vision impairment. Ophthalmic Physiol Opt. 2014;34(5):552-557.

12. Gill K, Mao A, Powell AM, Sheidow T. Digital reader vs print media: the role of digital technology in reading accuracy in age-related macular degeneration. Eye. 2013;27(5):639-643.

13. TapTapSee. Available from: http://www.taptapseeapp.com/. Accessed June 8, 2015.

14. VizWiz. Available from: http://www.vizwiz.org/. Accessed June 8, 2015.

15. Optelec. Available from: http://www.optelec.com/. Accessed June 8, 2015.

16. Walker R. An iPad app as a low-vision aid for people with macular disease. Br J Ophthalmol. 2013;97(1):110-111.

17. Peli E. Vision multiplexing: an engineering approach to vision rehabilitation device development. Optom Vis Sci, 2001;78(5):304-315.

18. Vargas-Martin F, Peli E. Augmented-view for restricted visual field: multiple device implementations. Optom Vis Sci. 2002;79(11):715-723.

19. Peli E, Luo G, Bowers A, Rensing N. Applications of augmented vision head-mounted systems in vision rehabilitation. J Soc Inf Disp. 2007;15(12):1037-1045.

20. Luo G, Peli E. Development and evaluation of vision rehabilitation devices. Presented at the 33rd Annual International Conference of the IEEE EMBS, Boston, MA, USA, August 30 to September 3, 2011.

21. Massof RW, Rickman DL. Obstacles encountered in the development of the low vision enhancement system. Optom Vis Sci. 1992;69(1): 32-41.

22. Culham LE, Chabra A, Rubin GS. Clinical performance of electronic, head-mounted, low-vision devices. Ophthalmic Physiol Opt. 2004;24(4):281-290.

23. Hwang AD, Peli E. Augmented edge enhancement for vision impairment using Google Glass. Optom Vis Sci. 2014;91(8):1021-1030.

24. Ianchulev T, Minckler DS, Hoskins HD, et al. Wearable technology with head-mounted displays and visual function. JAMA. 2014;312(17) 1799-1801.

25. Tarita-Nistor L, Gonzalez EG, Mandelcorn MS, Lillakas L, Steinbach MJ. Fixation stability, fixation location and visual acuity after successful macular hole surgery. Invest Ophthalmol Vis Sci. 2009;50(1): 84-89.

26. Gonzalez EG, Tarita-Nistor L, Mandelcorn ED, Mandelcorn M, Steinbach MJ. Fixation control before and after treatment for neovascular age-related macular degeneration. Invest Ophthalmol Vis Sci. 2011;52(7):4208-4213.

27. Tarita-Nistor L, Gonzalez EG, Markowitz SN, Steinbach MJ. Fixation characteristics of patients with macular degeneration recorded with the MP-1 microperimeter. Retina. 2008;28(1):125-133.

28. Crossland MD, Culham LE, Rubin GS. Fixation stability and reading speed in patients with newly developed macular disease. Ophthalmic Physiol Opt. 2004;24(4):327-333.

29. Schuchard RA. Preferred retinal loci and macular scotoma characteristics in patients with age-related macular degeneration. Can J Ophthalmol. 2005;40(3):303-312.

30. Contestabile MT, Recupero SM, Palladino D, et al. A new method of biofeedback in the management of low vision. Eye. 2002;16(4):472-480.

31. Giorgi D, Contestabile MT, Pacella E, Balacco Gabrieli C. An instrument for biofeedback applied to vision. Appl Psychophysiol Biofeedback. 2005;30(4):389-395.

32. Morales MU, Saker S, Amoaku WM. Bilateral eccentric vision training on pseudovitelliform dystrophy with microperimetry biofeedback. BMJ Case Rep. 2015;2015:bcr2014207969.

33. Vingolo EM, Cavarretta S, Domanico D, Parisi F, Malagola R. Microperimetric biofeedback in AMD patients. Appl Psychophysiol Biofeedback. 2007;32(3-4):185-189.
34. Vingolo EM, Salvatore S, Cavarretta S. Low-vision rehabilitation by means of MP-1 biofeedback examination in patients with different macular diseases: a pilot study. Appl Psychophysiol Biofeedback. 2009;34(2):127-133.

35. Nistor LT, Gonzalez EG, Markowitz SN, Steinbach MJ. Plasticity of fixation in patients with central vision loss. Vis Neurosci. 2009;26(5-6): 487-494.

36. Grenga PL, Trabucco P, Meduri A, Fragiotta S, Vingolo EM. Microperimetric biofeedback in a patient with oculocutaneous albinism. Can J Ophthalmol. 2013;48(5):e105-e107.

37. Vingolo EM, Salvatore S, Domanico D, Spadea L, Nebbioso M. Visual rehabilitation in patients with myopic maculopathy: our experience. Can J Ophthalmol. 2013;48(5):438-442.

38. Verboschi F, Domanico D, Nebbioso M, Corradetti G, Scalinci SZ, Vingolo EM. New trends in visual rehabilitation with MP-1 microperimeter biofeedback: optic neural dysfunction. Funct Neurol. 2013;28(4): 285-291.

39. Toto L, Di Antonio L, Mastropasqua A, De Nicola C, Mastropasqua L. Rehabilitation with MP1 biofeedback training of a posterior microphthalmos case. Can J Ophthalmol. 2013;48(5):e107-e111.

40. Sabel BA, Kasten E. Restoration of vision by training of residual functions. Curr Opin Ophthalmol. 2000;11(6):430-436.

41. Sabel BA, Kenkel S, Kasten E. Vision restoration therapy (VRT) efficacy as assessed by comparative perimetric analysis and subjective questionnaires. Restor Neurol Neurosci. 2004;22(6):399-420.

42. Vingolo EM, Salvatore S, Grenga P, Limoli PG. Visual training in retinitis pigmentosa patients: neural plasticity and function recovery. In: Catlin RB, editor. Retinal Degeneration: Causes, Diagnosis and Treatment. New York, NY, USA: Nova Publisher; 2009.

43. Vingolo EM, Salvatore S, Limoli PG. MP-1 Biofeedback: luminous pattern stimulus versus acoustic biofeedback in age related macular degeneration (AMD). Appl Psychophysiol Biofeedback. 2013;38(1):11-16.

44. Baker CI, Peli E, Knouf N, Kanwisher NG. Reorganization of vision processing in macular degeneration. J Neurosci. 2005;25(3):614-618.

45. Baker CI, Dilks DD, Peli E, Kanwisher NG. Reorganization of visual processing in macular degeneration: replication and clues about the role of foveal loss. Vision Res. 2008;48(18):1910-1919.

46. Amore FM, Paliotta S, Silvestri V, Piscopo P, Turco S, Reibaldi A. Biofeedback stimulation in patients with age-related macular degeneration: comparison between 2 different methods. Can $J$ Ophthalmol. 2013;48(5):431-437.

47. Humayun MS, Dorn JD, da Cruz L, et al. Interim results from the International Trial of Second Sight's visual prosthesis. Ophthalmology. 2012;119(4):779-788.

48. Zrenner E, Bartz-Schmidt KU, Benav H, et al. Subretinal electronic chips allow blind patients to read letters and combine them to words. Proc Biol Sci. 2011;278(1711):1489-1497.

49. Chen SJ, Mahadevappa M, Roizenblatt R, Weiland J, Humayun M. Neural responses elicited by electrical stimulation of the retina. Trans Am Ophthalmol Soc. 2006;104:252-259.

50. Ahuja AK, Dorn JD, Caspi A, et al. Blind subjects implanted with the Argus II retinal prosthesis are able to improve performance in a spatialmotor task. Br J Ophthalmol. 2011;95(4):539-543.

51. Dorn JD, Ahuja AK, Caspi A, et al. The detection of motion by blind subjects with the Epiretinal 60-Electrode (Argus II) retinal prosthesis blind subjects and motion detection. JAMA Ophthalmol. 2013;131(2):183-189.

52. Marc RE, Jones BW, Anderson JR, et al. Neural reprogramming in retinal degeneration. Invest Ophthalmol Vis Sci. 2007;48(7):3364-3371.

53. da Cruz L, Coley BF, Dorn J, et al. The Argus II epiretinal prosthesis system allows letter and word reading and long-term functions in patients with profo vision loss. Br J Ophthalmol. 2013;97(5):632-636. 


\section{Publish your work in this journal}

Clinical Optometry is an international, peer-reviewed, open access journal publishing original research, basic science, clinical and epidemiological studies, reviews and evaluations on clinical optometry. All aspects of patient care are addressed within the journal as well as the practice of optometry including economic and business analyses. Basic and clinical

Submit your manuscript here: http://www.dovepress.com/clinical-optometry-journal

research papers are published that cover all aspects of optics, refraction and its application to the theory and practice of optometry. The manuscript management system is completely online and includes a very quick and fair peer-review system, which is all easy to use. Visit http://www.dovepress. com/testimonials.php to read real quotes from published authors. 